\title{
Chiari Malformation in Adults: A Review of 40 Cases
}

\author{
David D.R. Eisenstat, Mark Bernstein, J.F. Ross Fleming, R.G. Vanderlinden \\ and Hart Schutz
}

\begin{abstract}
Forty adult patients (average age 40 years), with the clinical and radiological features of the Chiari malformations, were seen at the Toronto Western Hospital between 1967 and 1984. Surgical confirmation of the diagnosis was obtained in 32 cases; of these, 23 were classified as Chiari I malformation while 9 fulfilled the anatomic criteria of Chiari II. The patient population consisted of 22 males and 18 females. Common presenting symptoms included head and neck pain $(60 \%)$, sensory complaints $(60 \%)$, upper extremity weakness $(42 \%)$, and gait disturbance $(40 \%)$. Neurological findings included signs of central cord dysfunction (73\%), long-tract motor and/or sensory findings (58\%), brainstem signs (38\%), cerebellar dysfunction (18\%), and increased intracranial pressure (15\%). The majority of patients underwent myelography with or without computed tomography of the cervical-medullary junction. Two recent patients had $0.15 \mathrm{~T}$ MRI scans which helped demonstrate an intramedullary syrinx. Thirty-three patients underwent 47 operative procedures (discounting spinal fusion and CSF shunt revisions). Open surgical management was performed in 32 patients, with CSF shunting along in one patient. Five patients (15\%) incurred surgical complications within a six week postoperative period. Follow-up to date, ranges from one month to 11 years. In the 33 surgically treated patients, 18 are improved $(55 \%), 10$ are neurologically stable $(30 \%)$, and five have worsened clinically (15\%), including one death. Based on this study it appears that the Chiari II malformation may be more common in adults than previously recognized. Surgical intervention has a favourable outcome in the majority of patients but a significant proportion continue to deteriorate.
\end{abstract}

RÉSUMÉ: Malformation de Chiari chez l'adulte: à propos de $\mathbf{4 0}$ cas. Quarante patients adultes (âge moyen 40 ans) présentant un tableau clinique et radiologique de malformation de Chiari. ont été examinés au "Toronto Western Hospital" entre 1967 et 1984. Le diagnostic fut confirmé chirurgicalement dans 32 cas; parmi ceux-ci, 23 furent classifiés comme étant des malformations de Chiari de type I, alors que les 9 autres correspondaient aux critères anatomiques du type II. Vingt-deux étaient des hommes et 18 étaient des femmes. Les motifs de consultation les plus fréquents étaient des douleurs à la tête et au cou $(60 \%)$, des problèmes sensitifs $(60 \%)$, de la faiblesse aux membres supérieurs $(42 \%)$ et des troubles de la démarche $(40 \%)$. A l'examen neurologique, on retrouvait des signes de dysfonction médullaire centrale $(73 \%)$, des anomalies des faisceaux moteurs et/ou sensitifs longs $(58 \%)$, des signes d'atteinte du tronc cérébral (38\%), une dysfonction cérébelleuse (18\%) et une augmentation de la pression intracrânienne (15\%). La plupart des patients subirent une myelographie de la jonction cervico-médullaire, avec ou sans tomographie assistée par ordinateur. Récemment, on a pu démontrer la présence d'un syrinx intra-médullaire à l'aide d'une scintigraphie $0.15 \mathrm{~T}$ MRI chez deux patients. On a procédé à 47 interventions chirurgicales chez trente-trois patients, sans compter les fusions spinales et les révisions de dérivation du LCR. Trente-deux patients ont subi un traitement chirurgical, un patient n'ayant subi qu'une dérivation du LCR. Cinq patients (15\%) ont présenté des complications chirurgicales post-opératoires en dedans de six semaines de l'intervention. A date, la période d'observation post-thérapeutique varie entre un mois et 11 ans. Parmi les 33 patients qui ont subi un traitement chirurgical, 18 sont améliorés (55\%), 10 sont stables au point de vue neurologique (30\%) et cinq sont empirés cliniquement (15\%), incluant un décès. En s'appuyant sur cette étude, il semble que la malformation de Chiari de type Il est probablement plus fréquente chez l'adulte qu'on ne le croyait antérieurement. Chez la majorité des patients, le traitement chirurgical donne des résultats favorables. Cependant, l'état d'une proportion appréciable des patients continue à se détériorer.

Can. J. Neurol. Sci. 1986: 13:22/-228 
Cleland first described the anomaly later referred to as the Arnold-Chiari malformation, in 1883. ' Chiari and Arnold in 1891 and 1894 respectively, ${ }^{2.3}$ reported their descriptions and students of Arnold later used a single eponymic term to describe the various abnormalities. ${ }^{4}$ More recently, Peach ${ }^{5,6.7}$ and Carme $\left.\right|^{8.9 .10}$ have reviewed these early reports and others, ${ }^{11.12 .13}$ and clearly delineate the anatomical features of the Chiari malformations (Table 1).

Table 1: Classical Pathological Findings in the Chiari Malformations [after Carmel (1972) and Peach (1965)]

\begin{tabular}{|c|c|c|}
\hline & Chiari I & $\begin{array}{c}\text { Chiari II } \\
\text { ("Arnold Chiari") }\end{array}$ \\
\hline \multicolumn{3}{|l|}{ cerebellar tonsils displaced into } \\
\hline upper cervical canal & Yes & Yes \\
\hline caudal dislocation of medulla & No & Yes \\
\hline caudal dislocation of inferior & 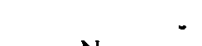 & \\
\hline $\begin{array}{l}\text { vermis and/or fourth ventricle } \\
\text { dorsal kinking of cervical- }\end{array}$ & No & Yes \\
\hline medullary junction & No & Yes, $>50 \%$ \\
\hline \multicolumn{3}{|l|}{ course of upper cervical nerve } \\
\hline roots & usually normal & usually upwards \\
\hline hydrocephalus & may be present & rarely absent \\
\hline syringomyelia & may be present & may be present \\
\hline
\end{tabular}

In both the Chiari I and Chiari II anomalies, the cerebellar tonsils are displaced downwards below the foramen magnum to variable levels of the upper cervical cord. The Chiari II anomaly, better known as the Arnold-Chiari malformation, usually includes caudal dislocation of the medulla, inferior vermis and/or the fourth ventricle and may involve dorsal kinking of the cervicalmedullary junction. The upper cervical nerve roots course rostrally. In both Chiari I and II malformations, hydrocephalus and syringomyelia may be present.

We present a series of 40 adult patients with the clinical and radiological features of the Chiari malformations seen at the Toronto Western Hospital between 1967 and 1984. Clinical presentation, radiological investigations, surgical management of 33 patients and prognosis following surgery are analyzed.

\section{Methods and Case Material}

A retrospective study was done of all charts in which a diagnosis of Chiari malformation presenting in adulthood was made between 1967 and 1984. Forty patients, 22 males and 18 females, were studied. The mean age at presentation was 39.8 years (range 13-65 years). The mean duration of symptoms prior to diagnosis was 6.7 years, with a great degree of variability; one patient had symptoms lasting one day, while another presented after suffering for 36 years.

Thirty-three patients were treated surgically and in 32 cases, the Chiari malformation was confirmed at operation. Complications related to surgery were included if their occurrence was during a six week postoperative period. Follow-up was dated from the time of the most recent surgical procedure and ranged from one month to 11 years, with a mean of 2.4 years. "Improved" denoted evidence on clinical examination, of objective improvement in the neurological status (eg. gait or motor strength) of the patient. In some patients, in whom pain or subjective visual disturbance was the presenting complaint, such an objective evaluation was not possible; a patient was considered improved if relief of the major presenting complaint was achieved. "Stable" denoted either a halt in the progression of symptoms and/or an unchanged neurological examination postoperatively.

\section{a) Symptoms}

Pain was the major complaint on presentation. Twenty-four $(60 \%)$ patients experienced headache or cervical pain while 14 (35\%) had shoulder girdle or arm pain. Sensory symptoms occurred in $24(60 \%)$; these included numbness or tingling, in upper as well as lower extremities, and loss of temperature sensation. Gait disturbance in $16(40 \%)$ patients was described as "unsteadiness" or loss of balance in 11 or as "spastic" in 5 patients. Upper extremity weakness was a complaint in 17 (43\%). These findings correlate well with larger studies. ${ }^{14,15,16.17}$ Visual disturbances, such as diplopia or blurring and/or oscillopsia, were a complaint in $12(30 \%)$; only $13 \%$ presented with visual complaints in series of 71 and 127 patients respectively. ${ }^{14.15}$ Table 2 lists the presenting symptoms in 40 patients.

Table 2: Presenting Symptoms in 40 Patients

\begin{tabular}{lcc}
\hline \hline \multicolumn{1}{c}{ Symptom } & Patients & Percent \\
\hline headache and cervical pain & 24 & $60 \%$ \\
sensory complaints & 24 & $60 \%$ \\
upper extremity weakness & 17 & $43 \%$ \\
gait disturbance & 16 & $40 \%$ \\
upper extremity pain & 14 & $35 \%$ \\
blurred vision & 12 & $30 \%$ \\
lower extremity weakness & 8 & $20 \%$ \\
lower cranial nerve (IX-X11) dysfunction & 4 & $10 \%$ \\
\hline
\end{tabular}

\section{b) Signs}

Patients with Chiari malformation presenting in adulthood can be grouped into 5 clinical syndromes. Other authors, however, have grouped neurological symptoms and signs into 3, 4 and 6 clinical syndromes. ${ }^{15.16 .18 .19,20}$ We have chosen to omit foramen magnum compression ${ }^{16,21}$ (ataxia, corticospinal and sensory deficits, cerebellar dysfunction and lower cranial nerve involvement) as it is less specific and precise in terms of clinical diagnosis. Our patients were assigned to one or more of the 5 syndromes (Table 3); an average of 2 clinical syndromes per patient was documented. Other studies have assigned patients to only one predominant syndrome. ${ }^{15.16 .18}$ The clinical syndromes are described as follows:

1) Central cord dysfunction was found in $29(73 \%)$ of our patients. This included pain, suspended dissociated sensory loss and segmental lower motor neuron weakness.

2) Long tract motor and/or sensory findings were seen in 23 (58\%) who presented with a combination of dorsal column involvement, pyramidal tract findings and spasticity.

3) Brain stem compression in $15(38 \%)$ patients included impaired cranial nerve V, V I1, IX-X 11 function and/or nystagmus (usually downbeating).

4) Cerebellar dysfunction was present in $7(18 \%)$ patients. Limb and/or truncal ataxia and/or nystagmus (horizontal) were the presenting signs.

5) Raised intracranial pressure signs were found in $6(15 \%)$ patients. 
Table 3: Clinical Syndromes in 40 Patients

\begin{tabular}{lcc}
\hline \hline \multicolumn{1}{c}{ Clinical Syndrome } & $\begin{array}{c}\text { 33 Surgical } \\
\text { Patients }\end{array}$ & Total Series \\
\hline 1) Central cord dysfunction & $25(76 \%)$ & $29(73 \%)$ \\
2) Long-tract motor and/or sensory & & \\
$\quad$ findings & $19(58 \%)$ & $23(58 \%)$ \\
3) Brainstem compression & $12(36 \%)$ & $15(38 \%)$ \\
4) Cerebellar dysfunction & $7(21 \%)$ & $7(18 \%)$ \\
5) Raised intracranial pressure & $6(18 \%)$ & $6(15 \%)$ \\
\hline
\end{tabular}

Table 4: Neuroradiological Investigations - 33 Surgical Patients

\begin{tabular}{cc}
\hline \hline \multicolumn{1}{c}{ Study } & Patients \\
\hline Myelography (iodine, air, metrizamide + delayed CT) & 29 \\
- wide cord & 24 \\
- tonsils displaced downward & 22 \\
- collapsing cord & 4 \\
Computed Tomography (alone + contrast) & $\underline{18}$ \\
- tonsils displaced downward & 15 \\
- syrinx & 9 \\
- dilated ventricles & 4 \\
- dye in central canal & 4 \\
- normal study & 3 \\
Magnetic Resonance Imaging & 2 \\
- syrinx & 2 \\
Cerebral Angiography & 1 \\
- PICA/tonsillar branches displaced & 9 \\
- hydrocephalus & 5 \\
Pneumoencephalography & 2 \\
- syrinx & 5 \\
- tonsils displaced downward & 2 \\
Cervical Spine X-ray & 2 \\
- degenerative changes & 22 \\
- normal study & 8 \\
- spina bifida occulta & 6 \\
- assimilation of atlas & 5 \\
- widened canal & 4 \\
\hline
\end{tabular}

Visual disturbances were found in $12(30 \%)$ patients. They presented with nystagmus, 9 of the horizontal type, 6 of the downbeating type and 2 of the rotatory type. Other ophthalmologic signs included absent corneal reflex in 5 patients (13\%), 2 with papilledema $(5 \%)$ and $6(15 \%)$ with a partial or complete Horner's syndrome. These findings are listed to emphasize that a careful examination of the vestibulo-ocular pathway may be useful in diagnosing a patient with adult-onset Chiari malformation.

c) Neuroradiological Investigations (in 33 surgically treated patients)

1) Skull films were done in only $17(52 \%)$ patients. Eight were normal studies, while 2 demonstrated platybasia; another showed basilar impression and a concave clivus. Two patients with raised ICP had a copper-beaten appearance of their calvaria.

2) Cervical-spine films were done in $22(67 \%)$ patients either as a separate study or as part of myelography. Eight showed degenerative changes, while in 6 a normal study was found. Spina bifida occulta was documented in 5 patients, 2 involving the cervical spine.
3) Pneumoencephalography and cerebral angiography were done in the years preceding computed tomography. In 2 patients, ventriculomegaly was demonstrated.

4) Myelography was performed in $29(88 \%)$ patients using various contrast media (air, iodine, metrizamide), and in recent years, metrizamide myelography has been combined with a delayed CT scan ( 16 patients). A widened cord was found in 24 patients $(83 \%)$ while caudal displacement of the cerebellar tonsils was noted in 22 patients $(76 \%)$, from the foramen magnum to the $\mathrm{C} 2$ spinal level.

5) Computed tomography was done separately in $19(55 \%)$ patients; sixteen had CT of head and spine while 2 had CT of head alone. A syrinx was demonstrated in 9, with the tonsils displaced downwards in 15 patients. Four patients had ventriculomegaly.

6) Magnetic resonance imaging (MRI) using an 0.15T magnetic field was done in 2 patients. In both, a syrinx was demonstrated but only one showed caudal displacement of the tonsils (Figure 1).

\section{d) Operative findings}

Based on surgical anatomy, 23 patients were classified as Chiari I and 9 as having Chiari II malformation. Tonsillar descent

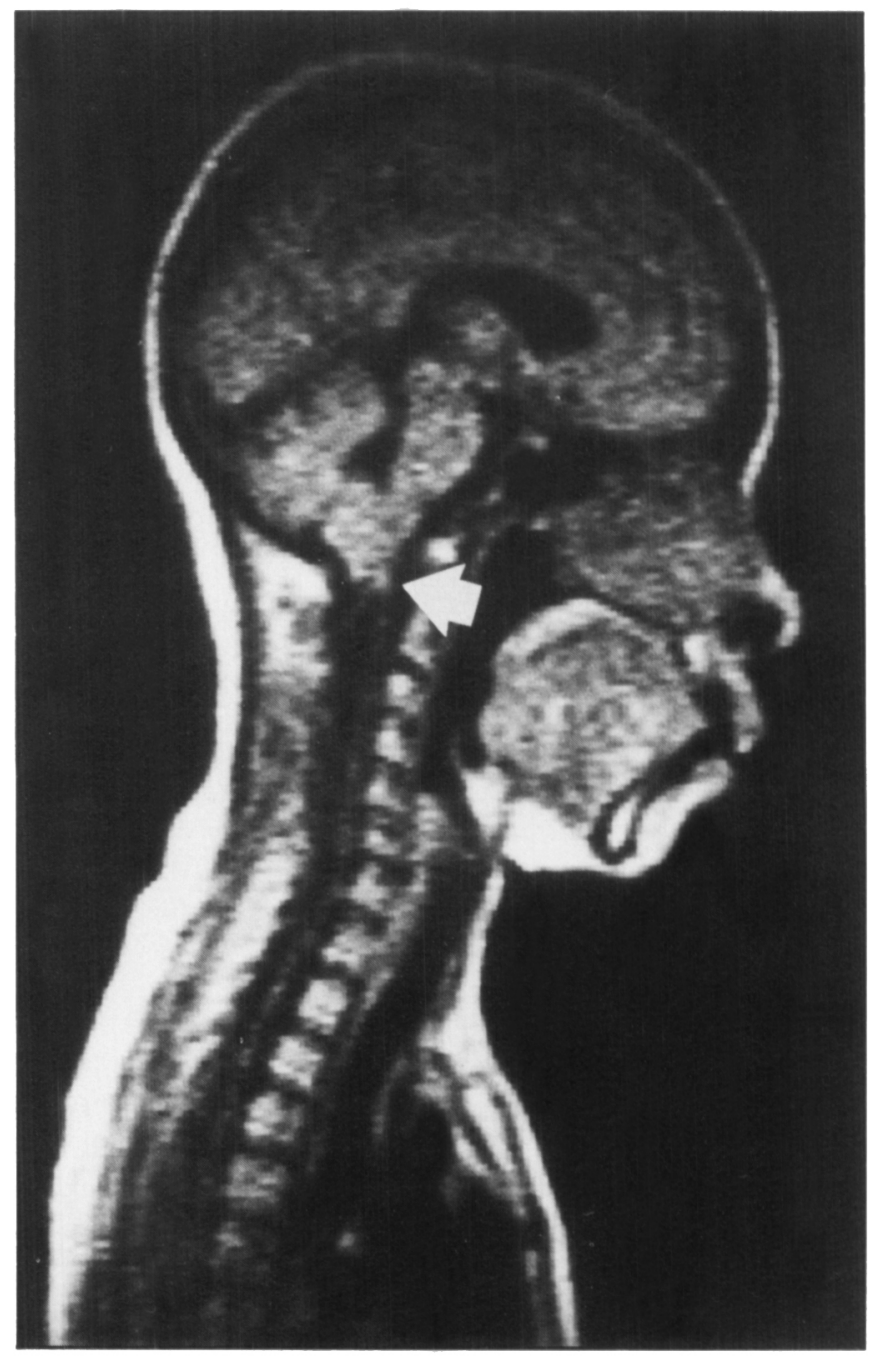

Figure l(a) - MRI scan showing tonsillar herniation (arrow) in Chiari I patient. 


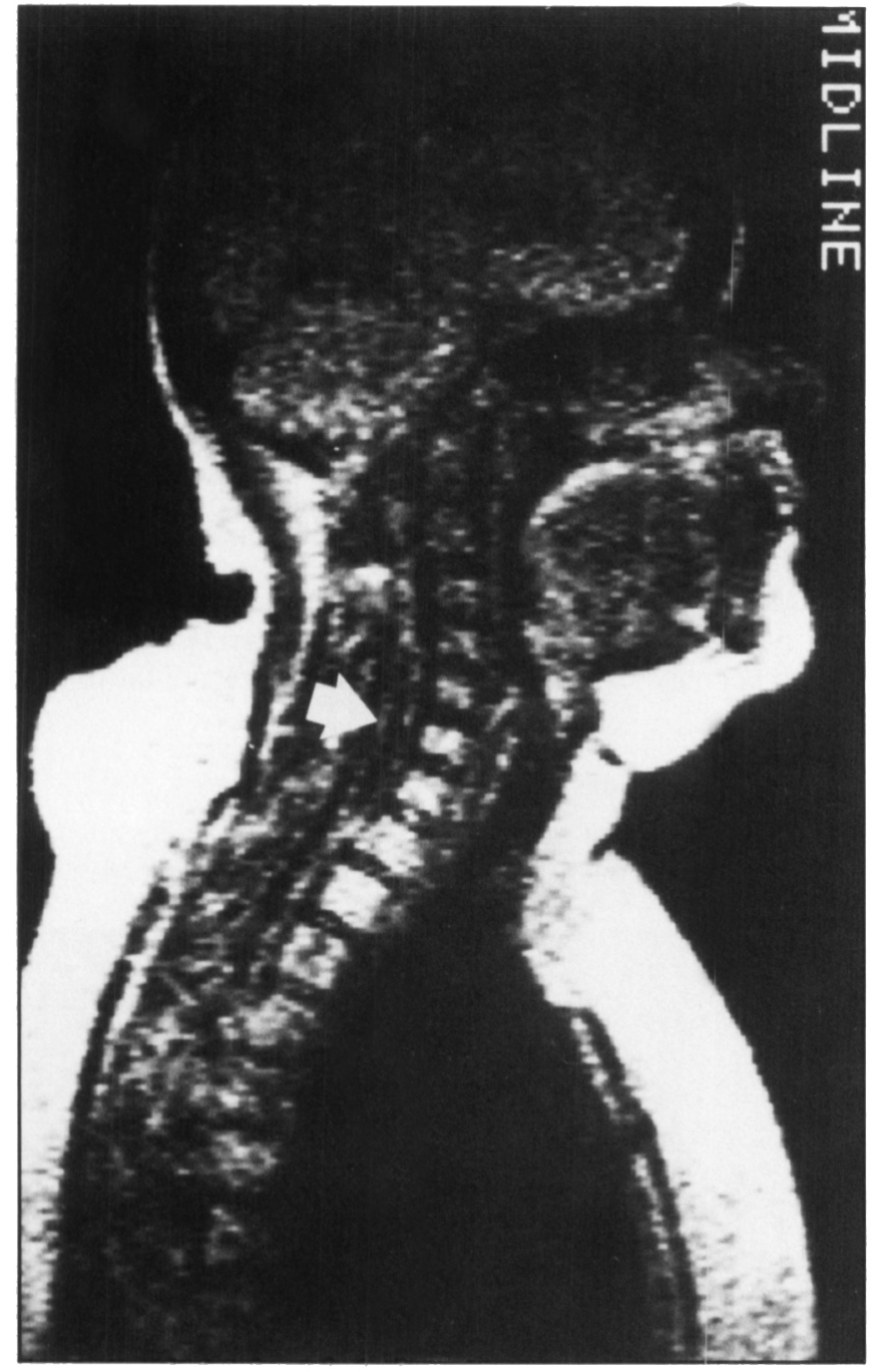

Figure $I(b)-M R I$ scan demonstrating cervical syrinx (arrow) in Chiari I patient.

was found in all patients having an open surgical procedure. Demonstration of a syrinx (direct visualization or aspiration) only occurred in 17 patients, although 25 presented with the clinical syndrome of central cord dysfunction. Kinking of the cervical-medullary junction was evident in $6(19 \%)$ patients, and caudal dislocation of the medulla was recorded in 2 . These criteria were the major determinants of a Chiari II malformation designation. Arachnoid adhesions were described in only 9 patients (28\%). The upper cervical nerve roots were upgoing or horizontal in 9 patients (28\%); this was seen in both Chiari I and II malformations (Table 5).

\section{e) Surgical treatment}

Figure 2 summarizes 33 patients who underwent 47 operatıve procedures (discounting spinal fusion and CSF shunt revisions). One patient had CSF shunting alone while the remaining 32 underwent posterior fossa decompression and cervical laminectomy, usually from $\mathrm{Cl}$ to $\mathrm{C} 3$ inclusive (the majority with duroplasty). Of these 32 patients, 9 had decompression alone, 3 had CSF shunting in addition, and the remaining 20 had plugging of the upper end of the central canal (obex) with a fascial or muscle plug. Twelve of these patients had additional or subse-
Table 5: Surgical Anatomy in 32 Patients

\begin{tabular}{lccc}
\hline \hline \multicolumn{1}{c}{ Findings at Surgery } & Chiari I (23) & Chiari II (9) & Total (32) \\
\hline Tonsillar descent & 23 & 9 & 32 \\
Syringomyelia & 13 & 4 & 17 \\
Kinking/buckling of cervical- & & & \\
$\quad$ medullary junction & 1 & 6 & 7 \\
Caudal dislocation of medulla & 0 & 2 & 2 \\
Arachnoid adhesions & 5 & 4 & 9 \\
Roots cephalad or horizontal & 6 & 3 & 9 \\
Dural Band & 4 & 1 & 5 \\
Skeletal anomalies & 2 & 2 & 4 \\
- Cl arch atresia & & & \\
- deep posterior fossa & & & \\
- small cisterna magna & & & \\
- bifid C1 & & 1 & 1 \\
Fourth ventricle cyst & 0 &
\end{tabular}

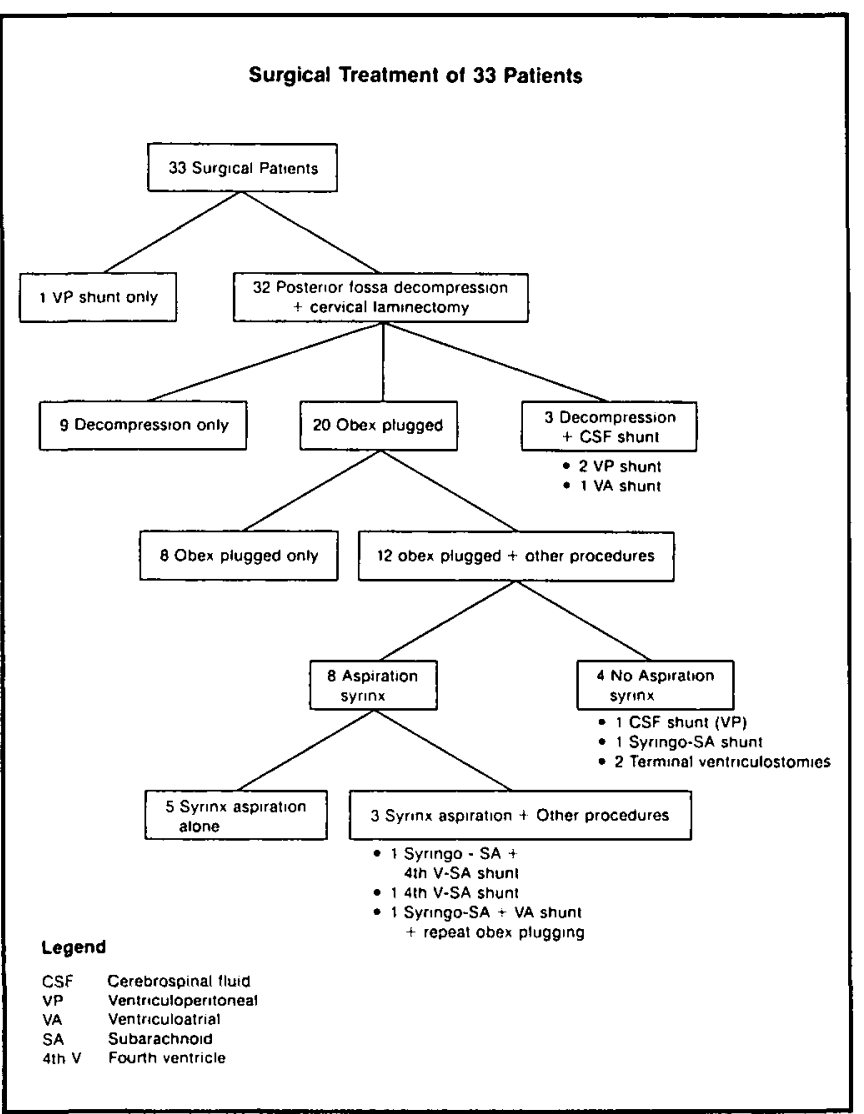

Figure 2 - Surgical procedures in 33 patients.

quent procedures. Eight had aspiration of an associated syrinx while 4 had various CSF shunts performed: terminal ventriculostomy (section of the filum terminale) in 2 patients, VP shunting in another patient and a syringo-subarachnoid shunt in the fourth patient. Three of 8 patients who had syrinx aspiration had other CSF shunts placed while the remaining 5 had this procedure alone. Syrinx aspiration resulted in cord collapse in 3 patients and in one patient the syrinx was identified but not drained. One patient, who later died, required 4 procedures over 5 years including posterior fossa decompression, laminectomy, obex plugging, a VA shunt and, finally, repeat obex plugging. 


\section{f) Surgical Results}

\section{(i) Surgical Complications}

Five (15\%) patients incurred surgical complications within a 6 week postoperative period. In 2 patients a CSF leak and a wound hematoma occurred respectively. Both were localized to the laminectomy site and were treated by aspiration. Hydrocephalus was diagnosed in a third patient postoperatively; he subsequently underwent a CSF shunting procedure. Hemiparesis resulted in another patient, but resolved spontaneously prior to discharge from hospital. A fifth patient complained of further sensory deficit in an extremity. No patients experienced respiratory complications which have been previously documented. ${ }^{15,18,22,23.24}$

\section{(ii) Surgical Outcome}

Results of surgical treatment are outlined in Tables 6, 7 and 8. Follow-up varied from one month to 11 years with a mean of 2.4 years. Outcome was analyzed with respect to surgical anatomy, surgical procedure and presenting clinical syndrome. Overall, $18(55 \%)$ are improved, $10(30 \%)$ are neurologically stable, and 5 (15\%) have worsened clinically including one death.

\section{DISCUSSION}

The Chiari malformations present in adulthood in variable fashion; often diagnosis and subsequent surgical treatment are delayed. Thorough clinical examination and a high index of suspicion remain important in diagnosis. Neuroradiological investigations, however, are essential to document tonsillar and/or vermian herniation and/or the presence of a syrinx.

Myelography with or without delayed contrast computed tomography (CT) was performed in 29 of 33 surgical patients; in $24(83 \%)$ patients, a widened cord, suggestive of a syrinx, was found. In several studies only $75-90 \%$ of syrinxes have been detected with water-soluble contrast CT scanning. ${ }^{22,25.26,27,28,29}$ A pre-operative accuracy of $87 \%$ combining metrizamide myelography with delayed contrast CT scanning has recently been reported. ${ }^{30}$

Magnetic resonance imaging (MRI) has been shown to be a useful adjunct in demonstrating pathology of the cervicalmedullary junction and in differentiating intramedullary spinal cord tumours from sprinxes. ${ }^{31,32,33,34}$ As more centres become familiar with its use, MRI will likely replace myelography with CT scanning as the diagnostic investigation of choice in those patients presenting with the clinical syndrome of central cord dysfunction, and those suspected of having a Chiari malformation.

The morphogenesis and pathophysiology of the Chiari malformations and syringomyelia has been described by several authors and numerous reviews are available in the neurological literature. ${ }^{13,17.20,23.29 .35-58}$ The nomenclature of the Chiari malformations has been the subject of controversy throughout the years. We have classified 23 of 32 patients as having Chiari I malformation, while 9 fulfilled the anatomic criteria of Chiari II malformation as originally described by $\mathrm{Chiari}^{2}$ and later clarified by Peach, ${ }^{5.6 .7}$ Carmel ${ }^{8.9 .10}$ and others. ${ }^{49.50 .52}$ Of 9 patients considered to have the Chiari II malformation, 6 had kinking of the cervical-medullary junction, 2 had caudal displacement of the medulla while one patient had a meningomyelocele at birth. Several authors have included caudal displacement of the medulla as part of the Chiari I malformation; ${ }^{48.59,60.61 .62}$ the earliest published reports, however, only included caudal medullary dislocation in their descriptions of the Chiari II or "ArnoldChiari" malformation. ${ }^{1,2.3 .4}$ Apparently, the Chiari malformations are a spectrum of related congenital anomalies and division into Chiari I or II may be an arbitrary one.

Surgical anatomy in our series was similar to other published reports. ${ }^{14.15 .16}$ Higher incidences of arachnoid adhesions $(40 \%),{ }^{14,15}$ dural bands $(30 \%),{ }^{15}$ and cephalad cervical roots $(39 \%)^{14}$ in other series could be due to variable reporting in the operative note. Levy et al report that only 106/127(83\%) clearly had cerebellar tonsils below the foramen magnum ${ }^{14}$ while the majority of other papers, including the present series, report that all patients have tonsillar descent evident at the time of operation. 15.16.18.19 $^{-19}$

At surgery, a syrinx was demonstrated in 17 patients, although 25 presented with the clinical syndrome of central cord dysfunction. In two recent series, only $41 \%$ and $32 \%$ had a syrinx demonstrated at operation. ${ }^{14.15}$ It can be postulated that the syrinx may not be visible after bony decompression has occurred. Often, the syrinx is below the region where cervical laminectomy is performed or perhaps it is not looked for. Another possibility is that the syrinx is manifested by central cord cavitation and the spinal cord itself is not widened.

Various surgical procedures have been advocated in the treatment of symptomatic patients with a Chiari malformation. 14.15.16.29.51.54.63.64 Twenty patients in our series had plugging of the obex in addition to posterior fossa decompression (Gardner's procedure). Within this group, 4 patients had various syrinx shunts (syringo-subarachnoid and/or fourth ventriclesubarachnoid) and 2 patients underwent terminal ventriculostomy. $A$ review of the literature regarding syrinx shunting reveals results differing only slightly from those with bony decompression alone. ${ }^{16.22 .29 .54 .65}$ Tator et al reported favourable results with syringo-subarachnoid shunting especially if there was no cerebellar tonsillar ectopia. ${ }^{65}$ Barbaro et al documented "good" or "fair" outcome in 12 of 15 with idiopathic syringomyelia treated by syringoperitoneal shunts. ${ }^{30}$ Lesoin et al reported a series of 8 patients treated by syringoperitoneal shunting and followed them from 3 to 12 months. Seven showed neurological improvement and I patient remained stable.$^{66}$ Cahan and Bentson reported no difference in patients undergoing Gardner's procedure who did or did not have a fourth ventricle to subarachnoid shunt placed in addition to the obex plugging. ${ }^{29}$

Terminal ventriculostomy was first described by Gardner in $1977 .{ }^{67}$ It has been advocated as a treatment for syringomyelia, especially when posterior fossa decompression has been followed by progression of symptoms. ${ }^{45.65 .67}$ Williams and Fahy reported 31 cases; 3 definitely improved and 10 patients did not show any improvement. The remaining 18 patients initially had marginal improvement, but the majority (12) continued to deteriorate after this procedure. ${ }^{40}$

Surgical outcome in our series compared favourably with other surgical series having 30 or more patients. ${ }^{14,15,16,17,22 .}$ 29.35.45.59.64.68.69.70 In the largest series of 127 patients, Levy et al reported $46 \%$ improvement, while $25 \%$ deteriorated in spite of any treatment. In patients with rapid progression of their disease, plugging of the central canal produced better results but overall, obex plugging did not gain an advantage. ${ }^{14}$ Paul et al reported subjective improvement in $82 \%$ and objective improvement in $70 \%$ of 71 patients. Early improvement was followed by later relapse in $21 \%$ of patients. ${ }^{15}$ 
Analysis of surgical outcome was accomplished by examining results with respect to surgical anatomy, surgical procedure and presenting clinical syndrome. Twenty-three patients with Chiari I (mean age 42.0 years) and 9 with Chiari II (mean age 33.1 years) malformation were classified (Table 6 ) but no difference was detected between these groups regarding outcome. Twelve patients had bony decompression alone or with CSF shunting procedures. Six (50\%) improved, $5(42 \%)$ were stable and one $(8 \%)$ worsened. Twenty patients had plugging of the obex in addition to bony decompression; of these 11 (55\%) improved, $5(25 \%)$ were stable and $4(20 \%)$ worsened clinically. In our series, plugging of the obex did not appear to produce a more favourable outcome (Table 7).

Identification of presenting clinical syndromes was helpful with respect to prediction of surgical outcome (Table 8). Four of $6(67 \%)$ with raised intracranial pressure, 9 of $12(75 \%)$ with brainstem compression, 5 of 7 (71\%) with cerebellar dysfunction and 12 of $19(63 \%)$ with long-tract findings improved with surgical treatment; however this data must be interpreted in light of the fact that most patients were assigned 2 or more clinical syndromes. Only 13 of $25(52 \%)$ with central cord dysfunction improved while $7(28 \%)$ remained stable and 5 (20\%) continued to decline neurologically. Of the 8 operated

Table 6: Results in Surgically Treated Patients by Anatomical Findings

\begin{tabular}{lcccc}
\hline \hline & Improved & Stable & Worse & Total \\
\hline Chiari I & 12 & 7 & 4 & 23 \\
Chiari II & 5 & 3 & 1 & 9 \\
Anatomy not visualized & & & & \\
$\quad$ (CSF shunt alone) & 1 & 0 & 0 & 1 \\
Total & 18 & 10 & 5 & 33 \\
Percent & $55 \%$ & $30 \%$ & $15 \%$ & $100 \%$ \\
\hline
\end{tabular}

Table 7: Results in Surgically Treated Patients by Surgical Procedure

\begin{tabular}{lcccc}
\hline \hline & Improved & Stable & Worse & Total \\
\hline $\begin{array}{l}\text { CSF shunt alone } \\
\text { Bony decompression alone }\end{array}$ & 1 & 0 & 0 & 1 \\
$\quad$ (BD) & 6 & 2 & 1 & 9 \\
BD + CSF shunt & 0 & 3 & 0 & 3 \\
BD + obex plugging & 5 & 2 & 1 & 8 \\
BD + obex plugging + & & & & \\
$\quad$ other CSF drainage & 4 & 0 & 0 & 4 \\
BD + obex plugging + & & & & \\
$\quad$ syrinx aspiration & 2 & 2 & 1 & 5 \\
BD + obex plugging + & & & & \\
$\quad$ syrinx aspiration + other & 0 & 1 & 2 & 3 \\
Total & 18 & 10 & 5 & 33 \\
Percent & $55 \%$ & $30 \%$ & $15 \%$ & $100 \%$ \\
\hline & & & &
\end{tabular}

Table 8: Results in Surgically Treated Patients by Clinical Presentation

\begin{tabular}{lcccc}
\hline \multicolumn{1}{c}{ Clinical Syndrome } & Improved & Stable & Worse & Total \\
\hline Central cord dysfunction & 13 & 7 & 5 & 25 \\
Long-tract motor and/or & & & & \\
$\quad$ sensory findings & 12 & 3 & 4 & 19 \\
Brainstem compression & 9 & 3 & 0 & 12 \\
Cerebellar dysfunction & 5 & 1 & 1 & 7 \\
Raised ICP & 4 & 1 & 1 & 6 \\
\hline
\end{tabular}

patients without any signs of central cord dysfunction preoperatively, 5 have improved $(63 \%)$ while 3 are stable. Paul et al and others note that in patients with the syndrome of central cord dysfunction there is a tendency for relapse $;^{15}$ review of earlier series shows that about 1 in 5 patients obtaining early postoperative improvement will deteriorate clinically over time. $^{14,16,18,22,23}$ Those with cerebellar dysfunction and/or raised ICP usually do not have late postoperative deterioration. 14.15 .16

Most series (including ours) represent relatively small numbers of patients and comparisons of treatment regimes are not amenable to statistical analysis. However, based on our series and the literature reviewed, we are proposing a recommended approach to the diagnosis and surgical treatment of patients having adult-onset Chiari malformation (Figure 3). A thorough

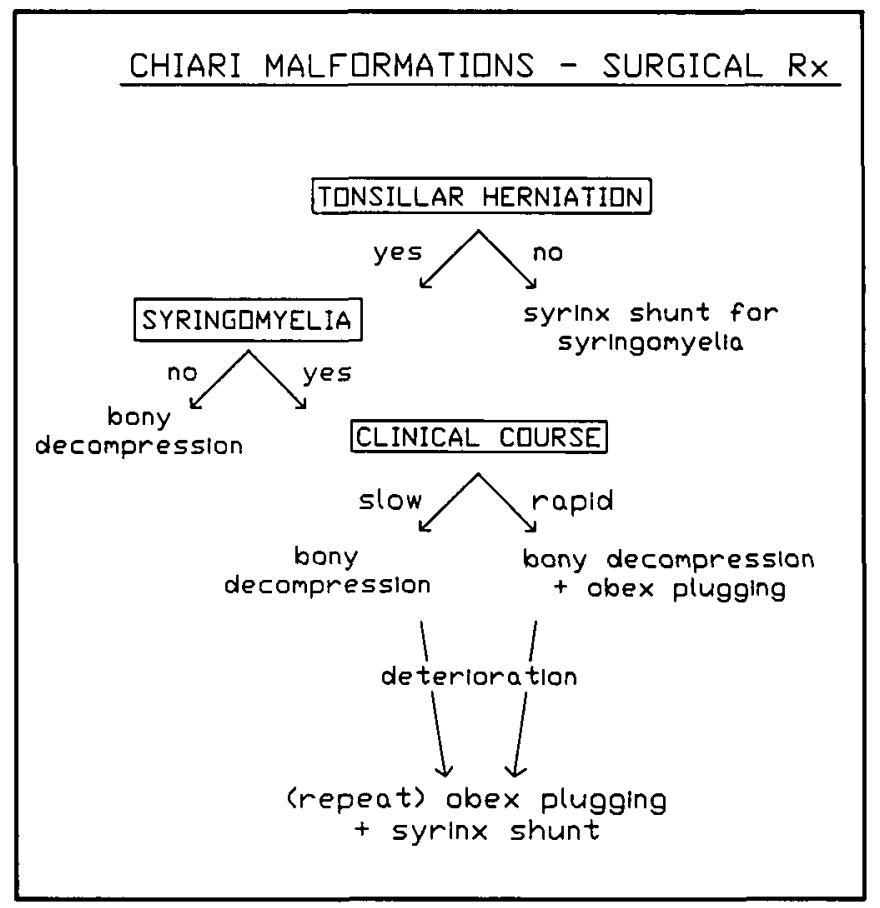

Figure 3(a) - Flow chart for recommended surgical management of adult patients with Chiari malformation. Bony decompression includes duroplasty.

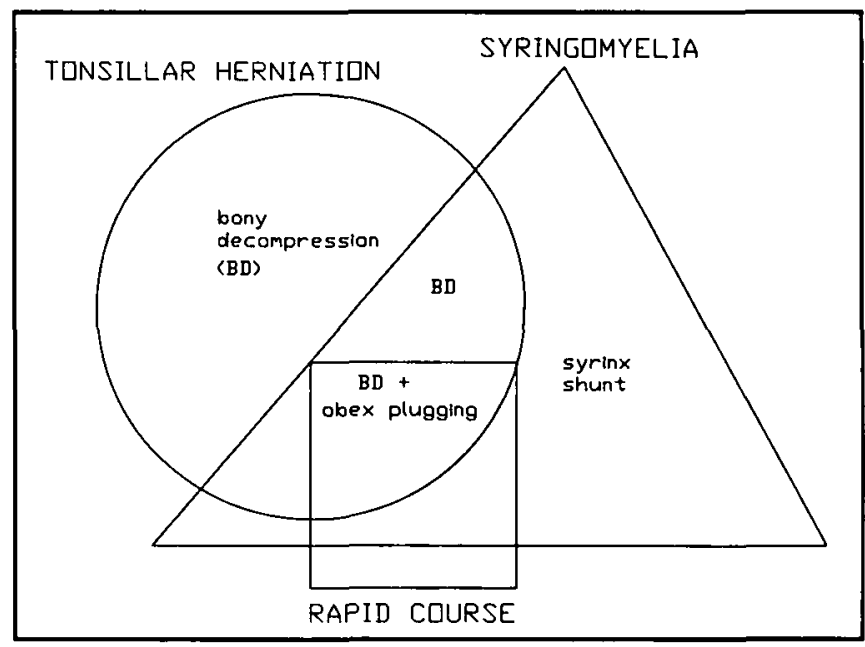

Figure 3(b) - Venn diagram summarizing flow chart. Bony decompression includes duroplasty. 
history and physical examination must precede any neuroradiological investigations, which at present should include both metrizamide myelography with delayed contrast $\mathrm{CT}$ scanning and magnetic resonance imaging (MRI). If there is evidence of syringomyelia but not of tonsillar herniation, syringosubarachnoid or syringoperitoneal shunting is recommended. Suboccipital craniectomy and cervical ( $\mathrm{Cl}$ to $\mathrm{C} 3$ ) laminectomy (ie. bony decompression) with duroplasty, should be done if there is tonsillar herniation but no syringomyelia. If tonsillar herniation is present along with demonstration of a syrinx, one should consider the clinical course of the patient. A rapidly progressive course (a few months or less) would suggest treatment with bony decompression and plugging of the obex. A long, protracted course would suggest that bony decompression alone is adequate. Follow-up over several years is requisite; with subsequent clinical deterioration of the patient, the clinician could consider (repeat) obex plugging or syringoperitoneal/ syringo-subarachnoid shunting in addition to procedures already performed. Other CSF shunting techniques are not recommended, nor are multiple procedures done at the time of the initial operation.

Follow-up of patients with Chiari malformations often poses some difficulties regarding objective assessment. Frequently, the presenting symptom such as pain or visual disturbance cannot be quantitatively tested and the clinician must depend upon subjective reports. It may be useful in patients with nystagmus to assess this finding quantitatively, both pre- and postoperatively, using electronystagmography (ENG). ${ }^{71,72,73,74}$ Brainstem auditory evoked responses have recently been used to document and follow patients. ${ }^{75.76}$ Pain may be semiquantitatively assessed using prepared standardized questionnaires such as the McGill Pain Questionnaire. ${ }^{77}$

The natural history of the Chiari malformations presenting in adulthood is not known and many patients have variable courses. ${ }^{14.78}$ Clearly, long-term follow-up is essential if we are to better understand the Chiari malformations and their clinical sequelae.

\section{ConClusions}

1. The Chiari II malformation may be more common in adults than previously recognized. Apparently, the Chiari malformations are a spectrum of related congenital anomalies and division into Chiari I or Chiari II may be an arbitrary one. There was no difference in surgical outcome between these 2 groups.

2. Magnetic resonance imaging (MRI) is a useful test in demonstrating cervical-medullary pathology. Neuroradiological investigation of patients with a Chiari malformation should include metrizamide myelography with delayed contrast computed tomography and MRI if available.

3. More than one-half of patients improved with surgery; of the remainder, $2 / 3$ became neurologically stable and $1 / 3$ continued to deteriorate. Patients presenting with clinical evidence of central cord dysfunction tend to have a less favourable outcome. Those with evidence of raised intracranial pressure, brainstem compression or cerebellar dysfunction, without central cord dysfunction may have a more favourable outcome.

4. Plugging of the obex, in our series, did not produce a more favourable outcome. We only recommend obex plugging for patients with tonsillar herniation, demonstration of a syrinx, and a rapidly progressive clinical course.

\section{REFERENCES}

1. Cleland J. Contribution to the study of spina bifida, encephalocele and anencephalus. J Anat Physiol 1883: 17: 257-291.

2. Chiari H. Ueber Veranderungen des Kleinhirns infolge von Hydrocephalie des Grosshirns. Deutsch Med Wschr 1891; 17; 1172-1175.

3. Arnold J. Myelocyste. Transposition von Gewebskeimen und Sympodie. Beitr Path Anat 1894: 16: 1-28.

4. Schwalbe E, Gredig U. Uber ent wicklungsstorungen des Kleinhirns Hirnstamms und Halsmarks ber Spina bifida. (Arnold'sche und Chiari'sche Misbildung). Beitr Pathol Anat U Allg Pathol 1907; 40: $132-194$

5. Peach B. Arnold-Chiari malformation: anatomic features of 20 cases. Arch Neurol (Chicago) 1965; 12: 613-621.

6. Peach B. Arnold-Chiari malformation with normal spine. Arch Neurol (Chicago) 1964: 10: 497.501.

7. Peach B. The Arnold-Chiari malformation: morphogenesis. Arch Neurol (Chicago) 1965: 12: 527-535.

8. Carmel PW. The Arnold-Chiari malformation. In: American Association of Neurological Surgeons, Section on Pediatric Neurosurgery, eds. Surgery of the Developing Nervous System. New York: Grune and Stratton, 1982: 61-77.

9. Carmel PW, Markesbery WR. Early descriptions of the ArnoldChiari malformation. The contribution of John Cleland. J Neurosurg 1972; 37: 543-547.

10. Carmel PW. Management of the Chiari malformation in childhood. Clin Neurosurg 1983; 30: 385-406.

11. Lebedeff A. Ueber die Entstehung der Anencephalie und Spina bifidia bei Vogeiln und Menschen. Virch Arch Path Anat 1881: 86: 263-298.

12. Penfield W, Coburn DF. Arnold-Chiari malformation and its operative treatment. Arch Neurol Psych 1938; 40:328-336.

13. List CF. Neurologic syndromes accompanying developmental anomalies of occipital bone, atlas and axis. Arch Neurol Psych 1941: 45: $577-616$

14. Levy WJ, Mason L, Hahn JF. Chiari malformation presenting in adults: A surgical experience in 127 cases. Neursurgery 1983: 12 : 337-390.

15. Paul KS, Lye RH, Strang FA et al. Arnold-Chiari malformation, review of 71 cases. J Neurosurg 1983; 58: 183-187.

16. Saez RT, Onofrio BM and Yanagihara T. Experience with ArnoldChiarimalformation, 1960 to 1970. J Neurosurg 1976;45:416-422.

17. Hankinson J. The surgical treatment of syringomyelia. In: Krayenbuhl $\mathbf{H}$, ed. Advances and Technical Standards in Neurosurgery, Vol. S. Wien: Springer-Verlag, 1978: 127-151.

18. Mohr PD, Strang FA, Sambrook MA et al. The clinical and surgical features in 40 patients with primary cerebellar ectopia (adult Chiari malformation). Q J Med 1977; 85-96.

19. Appleby A, Foster JB, Hankinson J et al. The diagnosis and management of the Chiari anomalies in adult life. Brain 1968:91: 131-139.

20. Banerji NK, Millar JHD. Chiari malformation presenting in adult life: Its relationship to syringomyelia. Brain 1974: 97: 157-168.

21. Meyer FB, Ebersold MJ, Reese DF. Benign tumours of the foramen magnum. J Neurosurg 1984; 61: 136-142.

22. Logue V, Rice-Edwards $M$. Syringomyelia and its surgical treatment - an analysis of 75 patients. J Neurol Neursurg \& Psych 1981: 44: 273-284.

23. Williams B. A critical appraisal of posterior fossa surgery for communicating syringomyelia. Brain 1978; 101: 223-250.

24. Mullan S, Raimondi AJ. Respiratory hazards of the surgical treatment of the Arnold-Chiari malformation. J Neurosurg 1962: 19: 675-678.

25. Pullicino, P, Kendall BE. Computed tomography of "cystic" intramedullary lesions. Neuroradiology 1982; $23: 117-121$.

26. Aubin $\mathrm{ML}$, Vignaud $\mathrm{J}$, Jardin $\mathrm{C}$ et al. Computed tomography in 75 clinical cases of syringomyelia. AJNR 1981; 2: 199-204.

27. Finn $S$, Rieux D, Fressinaud $P$ et al. Chiari type 1 malformation with hydromyelia: Findings at computerized metrizamide ventriculography. Surg Neurol 1979; 12: 227-229.

28. Forbes WSTC, Isherwood I. Computed tomography in syringomyelia and the associated Arnold-Chiari type I malformation. Neuroradiology 1978: 15: 73-78. 
29. Cahan LD, Bentson JR. Considerations in the diagnosis and treatment of syringomyelia and the Chiari malformation. J Neurosurg 1982; 27: 24-31.

30. Barbaro NM, Wilson CB, Gutin PH et al. Surgical treatment of syringomyelia: Favourable results with syringoperitoneal shunting. J Neurosurg 1984; 61: 531-538.

31. Lee BCP, Zimmerman RD, Manning JJ et al. MR imaging of syringomyelia and hydromyelia. AJNR 1985; 6: 221-228.

32. Spinos E, Laster DW, Moody DM et al. MR evaluation of Chiari I malformations at $0.15 T$. AJNR 1985; 6: 203-208.

33. Lee BCP, Deck MDF, Kneeland JB et al. MR imaging of the craniocervical junction. AJNR 1985; 6: 209-213.

34. Pojunas K, Williams AL, Daniels DL et al. Syringomyelia and hydromyelia: Magnetic resonance evaluation. Radiology 1984; 153: 679-683.

35. Barnett HJM, Foster JB, Hudgson P. Syringomyelia. London: WB Saunders, 1973.

36. Gardner WJ. Hydrodynamic mechanism of syringomyelia: Its relationship to myelocele. J Neurol Neurosurg \& Psych 1965; 28: 247-256.

37. Conway LW. Hydrodynamic studies in syringomyelia. J Neurosurg 1967; 27: 501-514.

38. Hall PV, Muller J, Campbell RL. Experimental hydrosyringomyelia, ischemia myelopathy and syringomyelia. J Neurosurg 1975; 43 : 464-470.

39. Hall PV, Turner M, Aichinger S et al. Experimental syringomyelia. The relationship between intraventricular and intrasyrinx pressures. J Neurosurg 1980; 52: 812-817.

40. Williams B, Fahy G. A critical appraisal of "terminal ventriculostomy" for the treatment of syringomyelia. J Neurosurg 1983;58: 188-197.

41. DeBattersby R, Williams B. Birth injury: A possible contributory factor in the aetiology of primary basilar impression. J Neurol Neurosurg \& Psych 1982; 45: 879-883.

42. Hall PV, Kalsbeck JE, Wellman HN et al. Radioisotope evaluation of experimental hydrosyringomyelia. J Neurosurg 1976;45: 181-187.

43. Newman PK, Terenty TR, Foster JB. Some observations on the pathogenesis of syringomyelia. J Neurol Neursurg \& Psych $1981 ; 44: 964-969$

44. Williams B. On the pathogenesis of syringomyelia: A review. J Roy Soc Med 1980; 73: 798-806.

45. Schlesinger EB, Antunes JL, Michelsen WJ et al. Hydromyelia: Clinical presentation and comparison of modalities of treatment. Neurosurgery 1981; 9: 356-365.

46. Guin PR. Arnold-Chiari malformation - a closer look. J Neurosurg Nurs $1985 ; 17: 45-52$.

47. Welch K. Shillito J, Strand R et al. Chiari I "malformation" - an acquired disorder? J Neurosurg 1981; 55: 604-609.

48. Schut L, Bruce DA. The Arnold-Chiari malformation. Orthop Clin North Am 1978; 9: 913-921.

49. Truex Jr, RC. Arnold-Chiari malformation. In: Buchheit WA and Truex Jr, RC, eds. Surgery of the posterior fossa. New York: Raven Press, 1979: 111-122.

50. French BN. The Arnold-Chiari malformation. In: Youmans JR, ed. Neurological Surgery, 2nd Ed. Philadelphia: Saunders, 1982: 1278-1288.

5l. Bertrand G. Anomalies of the craniovertebral junction. In: Youmans JR, ed. Neurological Surgery, 2nd Ed. Philadelphia: Saunders, 1982: 1482-1508.

52. Gilman S, Bloedel JR, Lechtenberg R. Disorders of the Cerebellum. (Contemporary Neurology Series 21). Philadelphia: FA Davis Co.. 1981: 269-278.

53. Teng $\mathrm{P}$, Papatheodorou $\mathrm{C}$. Arnold-Chiari malformation with normal spine and cranium. Arch Neurol (Chicago) 1965: 12:622-624.

54. Peerless SJ, Durward QJ. Management of syringomyelia: A pathophysiological approach. Clin Neurosurg 1983; 30: 531-576.
55. Rice-Edwards M. Syringomyelia. In: Austin GM, ed. The Spinal Cord, 3rd Ed. Tokyo: lgaku-Shoin, 1983: 753-766.

56. Lichtenstein BW. Distant neuroanatomic complications of spina bifida (spina dysraphism). Arch Neurol Psych 1942;47: 195-214.

57. Verbiest $\mathbf{H}$. The Arnold-Chiari malformation in adults without concomitant anomalies of the skull or the vertebral column. Folia Psych Neurol Neuroch Neerl 1953; 56: 544-551.

58. Gardner WJ. Anatomic features common to the Arnold-Chiari and the Dandy-Walker malformations suggest a common origin. Cleve Clin Q 1959; 26: 206-222.

59. Hankinson J. Syringomyelia and the surgeon. Mod Trends Neurol 1970; 5: 127-148.

60. McConnell AA, Parker HL, A deformity of the hindbrain associated with internal hydrocephalus. Its relation to the ArnoldChiari malformation. Brain 1938; 61 : 415-429.

61. Salam MZ, Adams RD. The Arnold-Chiari malformation. In: Vinken PJ, Bruyn GW, eds. Congenital Malformations of the Spine and Spinal Cord. Handbook of Clinical Neurology. Vol 32. Amsterdam/Oxford: North-Holland, 1978: 99-110.

62. Urich $\mathrm{H}$. Malformations of the nervous system, perinatal damage and related conditions in early life. $I n$ : Blackwood $\mathrm{W}$, Corsellis JAN, eds. Greenfield's Neuropathology, 3rd ed. London: Edward Arnold, 1976: 361-469.

63. Rhoton AL. Microsurgery of syringomyelia and syringomyelic cord syndrome. In: Schmidek HH and Sweet WH, eds. Operative Neurosurgical Techniques. Indications, Methods and Results. New York: Grune and Stratton, 1982: 103-124.

64. Rhoton AL. Microsurgery of Arnold-Chiari malformation in adults with and without hydromyelia. J Neurosurg 1976; 45: 473-483.

65. Tator $\mathrm{CH}$, Meguro K, Rowed DW. Favorable results with syringosubarachnoid shunts for treatment of syringomyelia. J Neurosurg 1982; 56: 517-523.

66. Lesoin F, Petit H, Thomas III CE et al. Use of syringoperitoneal shunt in the treatment of syringomyelia. Surg Neurol 1986; 25 : 131-136.

67. Gardner WJ, Bell HS, Poolos PH et al. Terminal ventriculostomy for syringomyelia. J Neurosurg 1977; 46: 609-617.

68. Garcia-Uria J, Leunda G, Carrilo R et al. Syringomyelia: Longterm results after posterior fossa decompression. J Neurosurg 1981; 54: 380-383.

69. Rhoton AL. Syringomyelia. In: Wilson CB, Hoff JT, eds. Current Surgical Management of Neurological Disease. New York: Churchill-Livingstone, 1980: 29-45.

70. Gardner WJ, Angel J. The cause of syringomyelia and its surgical treatment. Cleve Clin Q 1958; 25: 4-17.

71. Longridge NS, Mallinson AL. Arnold-Chiari malformation and the otolaryngologist: Place of magnetic resonance imaging and electronystagmography. Laryngoscope 1985; 95: 335-339.

72. Spooner JW, Baloh RW. Arnold-Chiari malformation: Improvement in eye movements after surgical treatment. Brain 1981 ; 104: $51-60$.

73. Chait GE, Barber HO. Arnold-Chiari malformation - some otoneurological features. J Otolaryng 1979; 8: 65-70.

74. Pedersen RA, Troost BT, Abel LA et al. Intermittent downbeat nystagmus and oscillopsia reversed by suboccipital cranioectomy. Neurology 1980; 30: 1239-1242.

75. Stone JL, Bouffard A, Morris R et al. Clinical and electrophysiologic recovery in Arnold-Chiari malformation. Surg Neurol 1983; 20: 313-317.

76. Holliday PO, Pillsbury D, Kelly DL et al. Brain stem auditory evoked potentials in Arnold-Chiari malformation: Possible prognostic value and changes with surgical decompression. Neurosurgery $1985 ; 16: 48-53$.

77. Melzack R. The McGill Pain Questionnaire: Major properties and scoring methods. Pain 1975: 1: 277-299.

78. Boman K, Iivanainen M. Prognosis of syringomyelia. Acta Neurol Scand $1967 ; 43: 61-68$. 